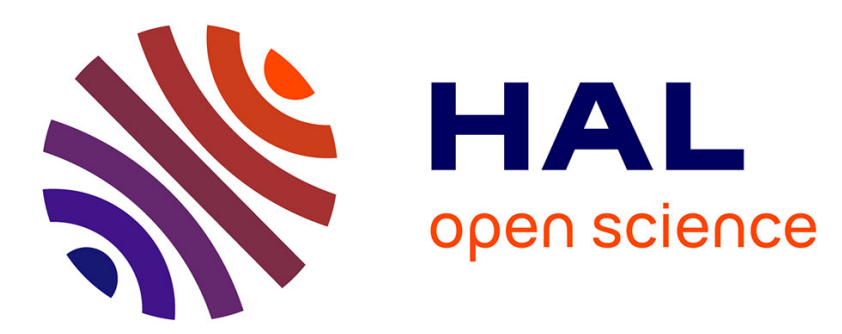

\title{
Supporting collaborative decision in architectural design with synchronous collocated 4D simulation and Natural User Interactions
}

Conrad Boton, Gilles Halin, Sylvain Kubicki

\section{- To cite this version:}

Conrad Boton, Gilles Halin, Sylvain Kubicki. Supporting collaborative decision in architectural design with synchronous collocated 4D simulation and Natural User Interactions. CDVE 2014, Sep 2014, Seattle, United States. hal-02890333

\section{HAL Id: hal-02890333 \\ https://hal.science/hal-02890333}

Submitted on 6 Jul 2020

HAL is a multi-disciplinary open access archive for the deposit and dissemination of scientific research documents, whether they are published or not. The documents may come from teaching and research institutions in France or abroad, or from public or private research centers.
L'archive ouverte pluridisciplinaire $\mathbf{H A L}$, est destinée au dépôt et à la diffusion de documents scientifiques de niveau recherche, publiés ou non, émanant des établissements d'enseignement et de recherche français ou étrangers, des laboratoires publics ou privés. 


\title{
Supporting collaborative decision in architectural design with synchronous collocated 4D simulation and Natural User Interactions
}

\author{
Conrad Boton $^{1}{ }^{2}$, Gilles Halin ${ }^{1}$ and Sylvain Kubicki ${ }^{12}$ \\ ${ }^{1}$ Public Research Centre Henri Tudor. 29, avenue JF Kennedy. \\ L-1855, Luxembourg-Kirchberg \\ ${ }^{2} \mathrm{CRAI}$ - Research Centre in Architecture and Engineering. \\ 2, rue Bastien Lepage. 54001 Nancy, France \\ gilles.halin@crai.archi.fr, \{conrad.boton, sylvain.kubicki\}@tudor.lu
}

\begin{abstract}
The work presented in this paper is part of a more comprehensive one which aims to propose appropriate natural user interactions to support collaborative decision making in synchronous $4 \mathrm{D}$ simulation. It presents the issue and previous works on natural user interfaces in $4 \mathrm{D}$ simulation. It also introduces a first prototype and a 4D case study from a real construction site.
\end{abstract}

Keywords: CSCW, 4D simulation, Human-Computer Interfaces, Natural User Interaction, Decision support, Architecture, Engineering and Construction, Collaborative 4D.

\section{Introduction}

According to Kvan, "in discussions about computer systems for collaborative design, their behaviours, specifications and implementation, the most fundamental arguments appear to be encountered on the issues of interaction" [9]. This is about both the interaction between participants and the interaction with the systems, and the issue have been well discussed in related literature [9, 10, 12]. But during the last decade, new devices (smartphones, tablets, digital tabletops, etc.) are appearing with new interaction capabilities. Construction practitioners are increasingly using such devices including, in addition to common mobile devices, the VCE [13], the TATIN [1], the ValueLab [7], and the iRoom [6]. Because of the diversity of innovative devices, it is important to take into account the novel interaction mechanisms they provide users with.

\section{Previous works on natural user interfaces in 4D simulation}

In the line of Building Information Modeling (BIM) approaches, collaborative 4D simulation is being increasingly used to visually simulate the construction process in order to detect constructability inconsistencies in the planning or in the design [3]. 4D 
simulation consists in linking a 3D model to the construction activities planning (time) to simulate the construction process over time [11]. In synchronous 4D simulation, all collaborative work participants are working on the 4D model at the same place at the same time [3]. If the interaction with 3D models has been extensively discussed in the literature, the interaction principles with the fourth dimension are much less studied $[4,8]$.

After Command Line Interfaces and Graphical User Interfaces, the last evolution in the Human-Computer Interaction paradigm lies in Natural User Interfaces (NUI). NUI reuse the human capabilities, behaviors and gestures to interact with IT systems [2]. NUI are not really new in 4D simulation. In 2002, Waly and Thabet proposed a virtual construction environment (VCE) for pre-construction planning [13]. They introduced an Interactive Virtual Interface (IVI) where users can graphically "drag and drop" elements from the 3D model and rebuild the building by putting side by side the components in the order received for the actual construction. The IVI offers intuitive and interesting interaction mechanisms such as 'click to take' or 'release to place' or 'navigate to the walk through' [13].

\section{A NUI me-fi prototype to support collaborative 4D decision}

In Human-Computer Interfaces design, "prototype fidelity expresses the similarity between the final user interface and the prototyped UI" [5]. Medium-fidelity (me-fi) tools "support designing UI mock-ups giving more importance to the contents than the style with which these contents are presented" [5]. The proposed prototype is composed of:

- a digital tabletop (Fig. 1c), used to display the 3D model, allowing all participants to visualize the model and providing the designer with appropriate natural interaction to make changes on the model (using a CAD software);

- 4 digital tablets (Fig 1a), used to display the planning, allowing each practitioner to make changes on his part of the planning. The validations performed by Zaidi [14] on lo-fi prototypes showed that interactions with the $3 \mathrm{D}$ model on tablets are not useful and actors prefer to interact with $3 \mathrm{D}$ on the tabletop;

- a whiteboard (Fig. 1b), used as viewer, displaying the 4D model resulting from the $3 \mathrm{D}$ model and the planning sequences.

The prototype business scenario is based on a case study from a real construction site in Luxembourg. The studied detail is about the construction sequence of wooden wall which is built through many steps with various subcontractors (woodwork, insulation, and cladding). Moreover windows have to be installed during and after the assembly of the wall itself. A smooth coordination among actors is then necessary to drill accurate reservations within walls and to ensure that the openings on the wall fit the windows dimensions. A 4D simulation for this case study showed that it is possible to involve at the early construction stage the sub-contractors in the construction process planning, and to provide them with a visual support in order to interact with the model and to find out the optimal construction sequences. 


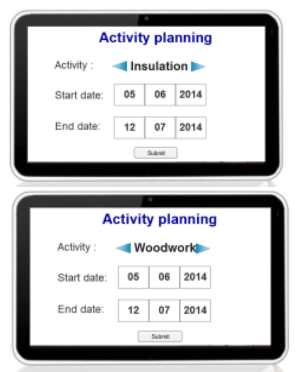

$1 \mathrm{a}$

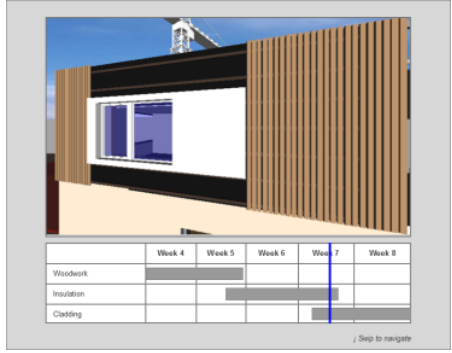

$1 \mathrm{~b}$

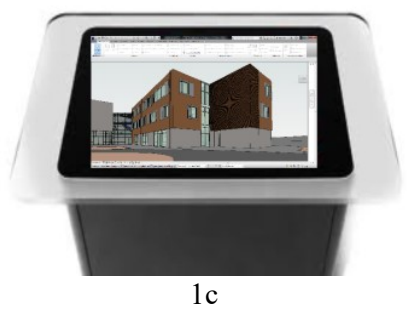

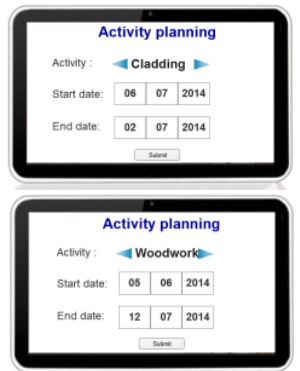

$1 \mathrm{a}$

Figure 1 : Devices composing the Me-Fi prototype

On the technical level, a built-in screen is integrated to the tabletop. This screen is multitouch and at least 12 points. A 4D software is implemented on the tabletop in order to manipulate the 3D/4D model with multitouch gestures. The digital tablets are connected to the tabletop and the via Wi-Fi connection.

The research project is still at its beginning and experimentations are planned to be conducted in architecture and engineering agencies. Such experimentations will be studied by some psychologists and specialists in ergonomics in order evaluate the usefulness and the usability of the proposed prototype for collective decision making supported by 4D models in a synchronous and collocated environment.

\section{Conclusion and future works}

In this paper, we presented the very first steps of an ongoing comprehensive work which aims at supporting collaborative decision making in architectural design with synchronous collocated 4D simulation and Natural User Interfaces. A first prototype and a 4D case study from a real construction site are introduced. These elements provide a good basis to understand the research project approach. Future works will validate the proposed prototype in the line of the business case. It will then be possible to propose a real NUI-based collocated and synchronous 4D system, according to the prototype. 


\section{Aknowledgement}

The authors would like to thank NeoBuild, the innovation cluster for sustainable construction in Luxembourg, for supporting this activity and providing the case study.

\section{References}

1. A. Jones et al.: Evaluating Collaboration in Table-centric Interactive Spaces. (2010).

2. Blake, J.: Natural user interfaces in .NET. WPF 4, Surface 2, and Kinect. Pearson Education (2012).

3. Boton, C. et al.: Collaborative $4 \mathrm{D} / \mathrm{nD}$ construction simulation: What is it? In: Luo, $\mathrm{Y}$. (ed.) Lecture Notes in Computer Science. Springer Berlin Heidelberg, Mallorca (2013).

4. Boton, C. et al.: Designing adapted visualization for collaborative 4D applications. Autom. Constr. 36, 0, 152-167 (2013).

5. Coyette, A. et al.: Multi-fidelity Prototyping of User Interfaces. In: Al., C.B. et (ed.) INTERACT 2007, LNCS 4662, Part I. pp. 150-164 (2007).

6. Fischer, M. et al.: Multi-stakeholder collaboration: The CIFE iRoom. International Council for Research and Innovation in Buildig and Construction. CIB w78 conference. pp. 12-14, Aarhus School of Architecture (2002).

7. Halatsch, J. et al.: Value Lab: a Collaborative Environment for the Planning of Future Cities. eCAADe 2008. pp. 507-514 (2008).

8. Halin, G. et al.: From collaborative business practices to user's adapted visualization services: Towards a usage-centered method dedicated to the AEC sector. CDVE'11 Proceedings of the 8th international conference on Cooperative design, visualization, and engineering. Lecture Notes in Computer Science. pp. 145-153 (2011).

9. Kvan, T.: Collaborative design: what is it? Autom. Constr. 9, 4, 409-415 (2000).

10. Lahti, H. et al.: Collaboration patterns in computer supported collaborative designing. Des. Stud. 25, 4, 351-371 (2004).

11. McKinney, K. et al.: Interactive 4D-CAD. Proceedings of the third Congress on Computing in Civil Engineering. pp. 383-389, Anaheim, CA, USA (1996).

12. Plume, J., Mitchell, J.: Collaborative design using a shared IFC building modelLearning from experience. Autom. Constr. 16, 1, 28-36 (2007).

13. Waly, A.F., Thabet, W.Y.: A Virtual Construction Environment for preconstruction planning. Autom. Constr. 12, 139-154 (2002).

14. Zaidi, F.: Identification des usages et interactions de la 4D collaborative synchrone exploitant une interface utilisateur naturelle. Mémoire de master. , Nancy (2013). 